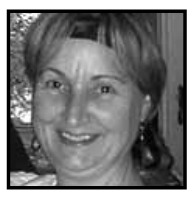

\title{
The Tides of Teaching: Rising to New Levels of Understanding Through Negotiation and Conversation in an Online Reading Course
}

\author{
Deborah Graham, St. Francis Xavier University
}

\section{ABSTRACT}

This study, conducted with eight elementary/ middle school teachers enrolled in an online reading course, asserts that through the development of relationships, the negotiation of a framework for study, and critical attention to generating and sustaining an environment conducive to learning, including interaction that promotes sincere conversation, that online learning can lead to substantial and meaningful professional insight. As a conceptual framework for this study I draw from images of the tides. Tides as metaphor provide me with a starting point for contemplation, an analogy from nature that, like teaching, has been an integral part of my life.

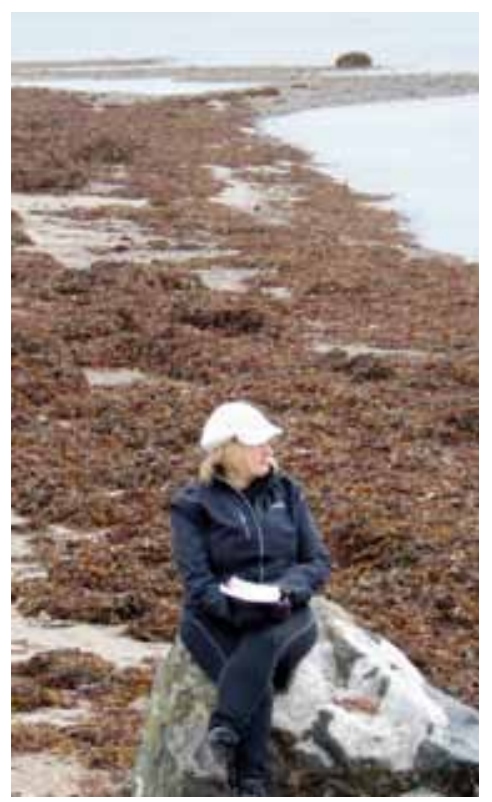

\section{Introduction}

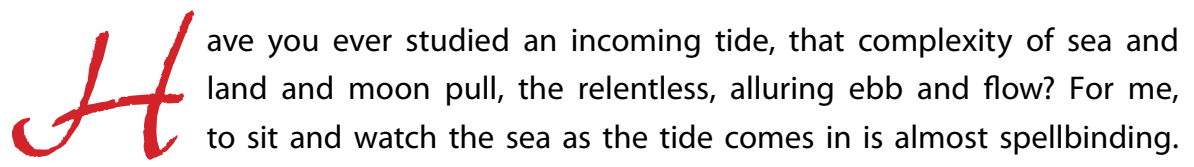


As I have watched the coming in and the going out of the tides over the years I have found an affinity with this daily rhythm. Having lived along the coast of Cape Breton Island, Nova Scotia, for more than 40 years, I have come to know the tides, the waters that lap the shores of our village. They have been as constant in my life as the sun that rises in the east over the small fishing community where I live and sets over St. George's Bay in the west. At first it might seem that this twice daily phenomenon, the rising and falling of the earth's water surface, is uncomplicated. But the motion of the tides entails a complex process governed by the laws of physics and mathematics. That which appears simple is often complex, as difficult to understand as how orbital forces produce oscillating currents and daily fluctuations in sea levels.

It has been my experience that understanding teaching is similar to interpreting the tides: on the surface, teaching may also appear effortless. However, investigation reveals teaching to be a complex profession, one elusive of definition (Graham, 2000). Still, we can begin to untangle the complexity through reflection and sincere, open conversation about our practice. Through such engagement, we can gain real insight about our practice and how best to face the daily challenges that come our way. Fiszer (2004) has pointed to the importance of a culture in which "teachers have opportunities to dialogue" (p. 16). Through dialogue, teachers gain "the space they need to refine their own experiences as a problem-solving exercise rather than a roadblock" (p. 16). However, the teacher interested in eliciting open and engaging conversation requires the right conditions. This study concerns the process I went through while teaching a fully online reading course for the first time and explains how I created an environment that encouraged open conversation. To verify the process, I probe one of the eight discussion threads of our course. As a conceptual framework for this study I draw upon the tides, which metaphorically provide me with a starting point for contemplation, an analogy from nature that, like teaching, has been an integral part of my life. 


\section{The Resonance of the Tides: Realizing the Conditions for Sincere Conversation in an Online Setting}

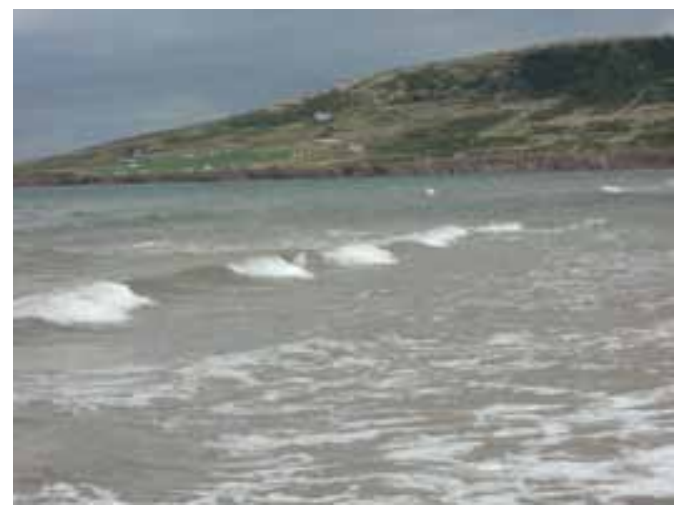

Incoming tides gently pushed by the winds can create a peaceful tempo. The rhythmic motion can be soothing, and those who listen carefully may be comforted by the sounds and the rhythm. In relation to conversation, the tides sometimes seem to beckon; when interests emerge, conversation can grow into a deep and meaningful interaction. This paper explores the power of engaging conversation, how it helps teachers gain awareness about their teaching. It postulates that conditions for such conversation can be created in an online setting.

There are of course obvious disadvantages to online learning, ranging from inequities surrounding technological abilities to apathy towards group work (Coleman, 2012; Roberts \& Mclnnerney, 2007) and the lack of physical presence and eye-to-eye contact. The disadvantages can make both teaching and learning in this environment difficult. Sometimes technical glitches occur that either take significant time to remedy, or cannot be remedied at all. I have found such things to interrupt the flow of the class, and I have had to respond with practical solutions that were necessarily imperfect. For instance, a technical problem resulted in my having to reconstruct class groups, but some of the rapport and level of comfort some of the teachers had in their original groups was thereby lost. Likewise, I have learned to make connections to people in online courses in the same or similar ways that I do face-to-face, but in a virtual environment I cannot re-create certain engaging and meaningful activities. I have realized that, as Meloncon (2007) points out, "if educators are changing teaching places, they need to redefine themselves in light of the change in landscape" ( pp. 37-38). Teaching an online reading course resulted in my redefining both what I do and what I am. I gained a new confidence in my ability to 
adapt to a new way of teaching and an affinity with teachers acquainted with the tools of 21st century learning.

As my understanding about online teaching grew, I began to recognize its benefits, benefits that have been well established through research (Palloff \& Pratt, 1999; Friesen \& Anderson, 2004; Hurt \& Brush, 2009). From easy accessibility, flexibility for scheduling, to experiencing a rewarding format there is significant evidence of the advantages that online learning can provide. Furthermore, as this study suggests, through the development of relationships, the negotiation of a framework for study, and critical attention to generating and sustaining an environment conducive to learning, including interaction that promotes sincere conversation, online learning can lead to substantial and meaningful professional insight.

\section{Observing an Incoming Tide From the Shoreline: Cultivating a Positive Environment for Online Learning}

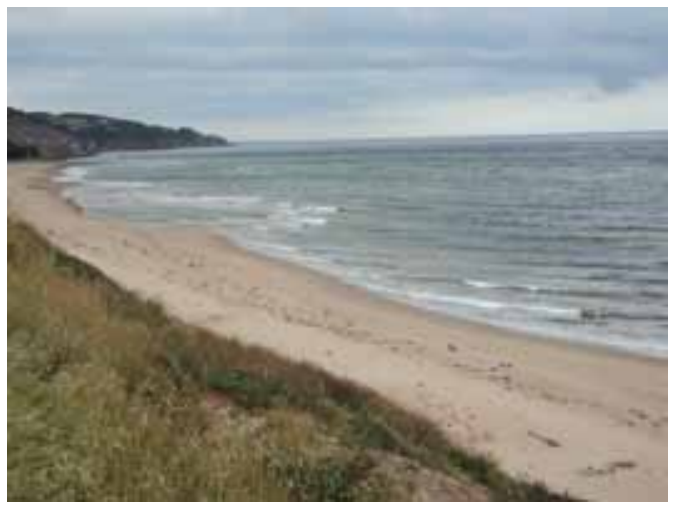

To gain a basic awareness of what an incoming tide looks like, it is helpful to observe the sea from a good vantage point. From an elevated position, one can see the vastness of the waters, the tide-washed rock formations that rise along the coast, and the ever-changing play of light dancing on the headland. Such a panoramic view allows a certain perspective. Like an observer of the tides, in the beginning I stood back and carefully considered what teaching an online course might be like, and all that it might encompass. Although I had engaged in online courses throughout my doctoral studies, this would be my first time teaching an online course, and 
I felt some trepidation. Online teaching meant facilitating learning while navigating some relatively foreign, uncharted waters. Yet, because of my years of working with teachers in various contexts, one thing I was certain of was that I needed to create a social learning environment where teachers would feel free to engage in open, honest conversation. Creating such conditions meant attending to details to help enable teachers to discuss their experiences in this way. In essence, sufficient knowledge and the right understanding, tone, and attitude would be crucial to shaping a liberating experience in which teachers might establish an "[i]nherent connectedness with others" (Atkinson, 1995, p. 4) and transform our loose group of course participants into a learning community.

Building a learning environment also meant starting with names and providing the opportunity to discuss areas of interest and other information. Each teacher in turn would begin a personal story, one that would continue to grow and would nurture the establishment of relationships conducive to professional learning. Naturally, I also wanted teachers to begin to make connections with the content of the course, and to realize that teaching reading in part means connecting with who we are as readers. Therefore, they were asked to begin sharing their literary histories (Tovani, 2000). In order to demonstrate my desire to work alongside these teachers, I modelled this activity by sharing my experience of an important book in my life, Barbara Joose's Mama Do You Love Me?, which I had left on my daughter's pillow the night before she was leaving home to attend university for the first time. The book tells a touching story about a daughter who attempts to find the limits of her mother's love; it is a book that encapsulated in many ways our own journey as mother and daughter. Sharing this experience helped to create an open environment in our online course and demonstrated that I too was a member of the group. It meant fostering an air of collaboration while facilitating the course; it meant being intentional in every way. As Lock (2006) puts it,

The realization of online learning communities to facilitate teacher professional development is a matter of carefully and deliberately designing dynamic learning environments that foster a learning culture. This requires a pedagogical framework ... where people engage in shared learning experiences mediated through technology. (p. 663)

While being intentional in my planning of the course, I also realized that community is born through negotiation and flexibility. In order to give credence to these words I invited our online community to reflect on the course syllabi and contribute views about how to shape it further to meet individual needs. This was 
most necessary, as the teachers enrolled, who were working towards their master's degrees, came from different backgrounds and professional experiences. They were divided on a variety of levels. Geographically, they came from all parts of the province of Nova Scotia; professionally, they assumed different roles, taught different grade levels, and held varying interests and beliefs about the teaching of reading. Conrad (2005) emphasizes a need to create "a general sense of connection, belonging, and comfort, that develops over time among members of a group who share purpose and commitment to a common goal" (p. 1). Creating space for each teacher to reflect on his or her own context and needs and to negotiate assignments, readings, and other course requirements created a sense of ownership and made the course more meaningful. Also, it provided more opportunity to learn from each other, or as Hargreaves (2003) points out, "[a] strong professional learning community brings together the knowledge, skills, and dispositions of teachers in a school or across schools to promote shared learning and improvement. A strong professional learning community is a social process for turning information into knowledge" (p. 170).

While sharing literary histories and co-constructing course expectations helped create a real space as opposed to a virtual one (Barab, Kling, \& Gray, 2004), the course took on greater meaning when teachers set up and responded to discussion threads and engaged in weekly conversations. When teachers began to converse, a forum was created that allowed them to investigate ideas, reflect on practice, provide support, test assumptions, and engage in pedagogical conversations-truly going far beyond just reading course texts and regurgitating information. Conversation at many times was deep and sincere, leading to the community members' greater understanding of themselves and of their profession. As Trathen and Moorman (2001) point out, "[t]elecommunication tools can facilitate the occurrence of dialogue" (p. 219). While this may seem obvious, discussion threads in this course proved more than a means of facilitation - they were a very effective tool for inviting genuine conversation and helping teachers gain deeper understanding of their practice.

\section{Methodology}

This study concerns the experiences of eight elementary and middle school teachers enrolled in an online reading course in the winter of 2009 offered by St. Francis Xavier University. The topic of the course was the nature of the reading process, and it was delivered using the Elluminate and Blackboard systems. I did not set out to conduct a study about what I would learn during the course, but when it was 
over many experiences remained with me, making me wish to delve deeper into why it had been successful. After the course, I applied for and was granted approval to conduct research from our ethics board at St. F X. This allowed me to send by email the participant information and consent forms to each member of our class. The students were thus informed of the nature and purpose of the study and their potential involvement in it. They were assured of their right to withdraw at any stage. Most importantly, they were informed that while there was a possibility that information derived during the study might be published, they would not be identified in any way, and that all possible measures (storing data securely, etc.) would be taken to ensure confidentiality. Each participant was asked to sign a hard copy of the participant consent form and return it to me. All of these details were completed prior to beginning the research.

The course unfolded over 12 weeks, participants meeting online weekly for a three-hour session. Throughout the 12 weeks, teachers were asked to complete assigned readings and to engage in a variety of activities. Through these activities they deeply explored the complex nature of the reading process. However, as the course went on, I found that it was through participation in conversations during virtual-class time and in ensuing discussion threads that teachers really began to think deeply about their practice. These discussion threads and weekly conversations, in which each teacher shared experiences, became the main portals through which we began to explore personal beliefs and convictions about reading instruction. They eventually provided the data that I chose to investigate.

Over the 12 weeks numerous discussion threads were generated, and afterwards I considered my purpose and what I hoped to achieve by way of analysis. In returning to the threads and guiding questions that teachers referred to as they initiated or responded to threads, I determined that two overriding questions would help me to shape narratives: 1) What connections had the teachers made between the readings and their own experiences as readers or as teachers of reading? and 2) What new questions, insights, and possibilities did the readers gain through the readings in relation to their understanding of the reading process?

Transcript analysis, then, was inductive: a process of attempting to find each teacher's story in relation to the two questions above; to derive from the discussion threads an understanding of the "complex journeys grounded in the everyday experiences of the participants" (Butler-Kisber, 2010, p. 68), as well as to record their awakenings in regard to the reading process. I read the transcripts closely, using different colours to highlight and distinguish experiences, questions, insights, and 
other points one from the other as I coded the information. Once this coding was completed I began to shape each narrative. In doing so I used an approach to that of Rhodes (found in Butler-Kisber, p. 71): ghostwriting - that is, creating a portrait of each participant's experience, sanctioned by the participant, in which the researcher is explicitly absent. This being said, I inserted my own words in order to "integrate the text" (p. 71) and to give the narrative continuity while preserving the context. After scripting each narrative I shared it with the participant and invited input and approval. Each participant responded favourably. What follows is an exploration of one participant's journey through the course. First, I share Lily's story, that which I constructed after analyzing of all of her threads of conversation during the course. Second, I share the fourth discussion thread that Lily initiated, and how teachers responded to her discussion. Each teacher has been given a pseudonym. Teachers responded by sharing connections they made and experiences that they had had during their own journey of uncovering this process.

\section{Shifting With the Tides: Teachers Engage in Sincere Conversation About Deciphering the Reading Process}

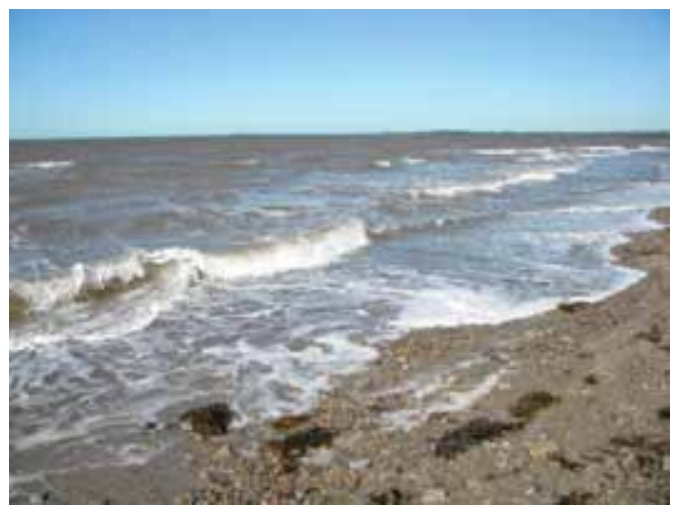

It is liberating to watch the waves roll in with the tide, to observe how they flow naturally as they wash up on the shoreline. Conversation between teachers can be similar: it can flow unrestrainedly and freely as experiences are shared and practice is discussed. Many times during our online reading course teachers engaged in such conversation and as a result reflected critically about the complexities of both understanding the reading process and teaching children to read. 


\section{Lily's Story: Refining the Craft of Teaching Through Shared Conversation}

Lily's participation in discussion threads resulted in questions about improving what she referred to as the craft of how to teach reading. As she reflected on her practice she asked the question, "How can I do better?" She continued to be introspective and pondered such matters as the techniques that she uses, her level of preparation and sensitivity to the needs of her students each day, her success in making reading a positive experience, and her ability to support students who struggle with reading. On several occasions she expressed having gained new insights. For example, following one discussion she admitted: "It was an eye opener for me as I read the statement that 'from grade 3 onward students received very little instruction in reading comprehension."' She also came to realize that many students today are disadvantaged by their circumstances, and consequently "there seems to be a bigger gap in language skills and acquisition." In sharing a conversation that she had had in her staff room, she came to see that "children need to expand their vocabulary and their use of language: So many of our students are not engaging in meaningful conversations at home due to different lifestyles."

Lily continually reflected on her own reading strategies, and through discussion demonstrated that insights gained by doing this helped her to understand her students better. As a child she had struggled in learning to read, and through our discussions she came to think that her struggle might benefit her students. She also indicated that as she engaged in discussions from the course readings she made several other connections both to her own personal journey in becoming a reader and to her own practice as a teacher of reading. Some of the connections that she made served to clarify what she already knew, while others helped her to see the reading process through new eyes. "I found that I began to reflect upon my personal reading and what it is that I do as a reader. I've never really thought about that before."

Lily raised many probing questions throughout the course, questions that indicated that she was reflecting on and thinking more deeply about her practice. Some of her questions had their roots in past experiences, such as when she asked,

How did I learn how to read? What methods were used then? If teachers used different strategies "back then," would I have struggled as much had I had the more updated strategies used now? How do I teach reading differently than I was taught? 
Overall, she gained a greater appreciation of the importance of asking questions in order to develop her own understanding of the reading process, and also of allowing her students to ask questions.

Lily also shared ideas that arose from our discussions and that looked to the future. For example, she talked about working with her students in new ways: "I now will be looking at fluency and comprehension in a different light." She realized that students "who take longer to read a passage sometimes retain more of the information than those who read quickly. I think we have to consider the child as an individual." She considered the future in broader terms, thinking about the need for universities to prepare student teachers to teach reading more effectively.

As Lily engaged in conversation with her colleagues, she reflected on past and present experiences and considered these as windows into her future teaching. She spoke about continually making "mental notes" and realizing new possibilities for transforming her teaching and helping her students, especially those who most need her support. She observed that "[b]elieving in oneself is very important" and that we need to consider what we believe as teachers. Lily shared new insights into several areas, including standardized testing, independent reading, differentiation of instruction, and working with the public. Finally, she stated:

The bottom line is [that] if students are not engaged in learning, it is difficult for them to learn. Education is constantly evolving and as a teacher, I too have to be willing to step out of my comfort zone and be willing to learn new things for the benefit of my students.

\section{Responding to Lily's Initiated Discussion Thread: Teachers Engage in Sincere Conversation About the Reading Process}

As Lily initiated the fourth discussion thread she begins by sharing a quotation from Donald Graves (a well-known author of many books on the writing process) about how powerful writing can be and how ideas can affect the lives of others. She spoke of a shift taking place in classrooms: the effort to include more nonfiction in students' reading, which until now has been strongly fiction-based. Lily talked about the need for students to see a sense of purpose in what they read and write, and how this can deepen understanding and motivate students to learn. She shared instances of her attempts to engage her students in real-life activities (authentic learning) some impromptu, others planned-and indicated that she would seek to do this even more in the future. Lily invited her colleagues to think about authentic literacy: 
seizing opportunities to include more authentic activities in their daily practice, integrating more informational text into their curricula, reflecting upon their own schooling and the authentic activities, or lack thereof, that they had had the opportunity to engage in.

Rachel was the first teacher to respond to Lily's thread and shared a memory of being younger and not recalling participating in many of the activities that she engages her students in:

When I learned to read and write there were no opportunities for authentic literacy activities. Although I do remember in Grade One being chosen to go to the pond beside the school with another student and collect tadpoles for the classroom. Unfortunately I do not remember doing anything else with the tadpoles.

Sarah, another teacher in the course, shared stories about her grade five class writing pen-pal letters to another class within the province, an authentic activity that motivated her students to read and write. She also mentioned their perusing newspapers, which led to starting a class newspaper:

They had found a real purpose to investigate newspapers. So their idea began to grow into a reality through lots of brain storming, researching, planning, negotiating, and hard work. As they discovered how to begin and write a newspaper, their questions led to other questions and considerations. Their enthusiasm led to a box being placed outside our classroom inviting the rest of the school to participate, asking questions to be answered through an advice column. One high academic student suggested how he might like to do a puzzle section. Even the more reluctant readers and writers were motivated into action. What an experience!

As Holly responded, she was reminded of her first year in a classroom after teaching music for several years. She described that year as her most authentic because she had had students engage in several different activities, such as using lemon juice to write letters to a stuffed frog and making ice cream in resealable bags in a snowbank. She went on to discuss the effect of what she perceived as changes in the school system:

Unfortunately for both me and the students, times changed as I moved up to Grade Three and Four with Provincial Assessments. I no longer felt that I 
had as much time to run with those teachable moments they talk about that I had so previously enjoyed! What a shame.

Holly shared memories of having created websites with her grade four/five class one year and of teddy bear exchanges another. She discussed how such activities really had a purpose and engaged her students. She also talked about changes she had experienced in recent years:

I look over my last couple of years in the classroom which were quite successful yet no longer was I allowed my couch and cushions in the reading corner, (allergies), the wooden park bench now in the reading corner was felt to be a hazard and the room looked very structured.

Finally, Holly shared her desire to create a more authentic environment for her students by turning their small school into a multi-aged learning environment. To this end, these were Holly's last words in the discussion: "The reading this week along with your stories and honesty has inspired me even more to go after the district to support a more 'Authentic Learning Environment' for our students!"

Sarah, Lily, Abigail, and Holly engaged in conversations about the lack of resources at their schools and how difficult it is to provide students with an authentic learning environment when financial funding is lacking. While they sought to find solutions to this problem, they bemoaned the challenge of covering so many outcomes when they have to struggle with outdated technology and other resource issues.

Ella agreed with the group and shared the following:

So many of you have written about such great authentic learning opportunities in your classrooms...it is great! I too agree that the learning comes alive when students become so engaged in these authentic learning situations. They become so involved with the experience that they don't even see that they are learning. They are able to lose themselves in the excitement of the activity, let their guards down and not worry about what the teacher is expecting them to do or say, and truly engage in the situation. It can be so tricky to balance all of the demands we are faced with... but these authentic learning opportunities are what really matter. I would love the time to work with other teachers in the same grade to develop more authentic learning situations. They are too important to miss out on. As was 
noted by Purcell-Gates and Duke [2004], "more authentic literacy activities are related to greater growth in the ability to read and write [new genres]." [Duke, Purcell-Gates, Hall, \& Tower, 2006, p. 354]

Ella recalled completing a science unit on living things the previous year and the excitement in her classroom as students rushed in each day to observe the growth of the bean plants they had started. She described how they kept diaries, drew diagrams, and made comparisons: "They were so actively engaged and just hearing them talk about their plants, compare theirs with others, and so forth made me realize how many more authentic learning opportunities I need to provide."

Millie closed the discussion thread by recalling an earlier story that Lily had shared about bringing a bicycle into the classroom and following the students' how-to instructions. She emphasized the need to provide authentic literacy learning for students, especially for those who struggle to read and write. She described a student she had taught in grade five who was a struggling reader, and how she discovered that what he really needed were more books to read that were not only at his reading level but also related to his interests. This student needed to be motivated to write:

I quickly motivated him by tapping into his love of fixing cars with his dad and his uncle..... off he went, authentically creating a piece of writing about working in cars with a drawing that labelled all of the parts of a car that he could name. I was delighted to see how impressed his classmates were with him. My bottom line: Authentic learning is the honey that will get you further than the vinegar (non-authentic literacy activities).

The braided conversations that flowed from Lily's discussion thread uncovered teachers' narratives of experience and how such experiences reflect their knowledge as teachers.

\section{Reflecting on the Tides of Teaching: The Promise of New Knowledge Gained Through Conversation, Negotiation, and Attention in an Online Setting}

If teaching an online course for the first time is rather like building a ship and setting sail on unknown seas, the experience of observing teachers engage in online learning, in weekly virtual classes and in discussion threads, is like charting the waters. Then, too, what the teachers went through in their process of discovery may 


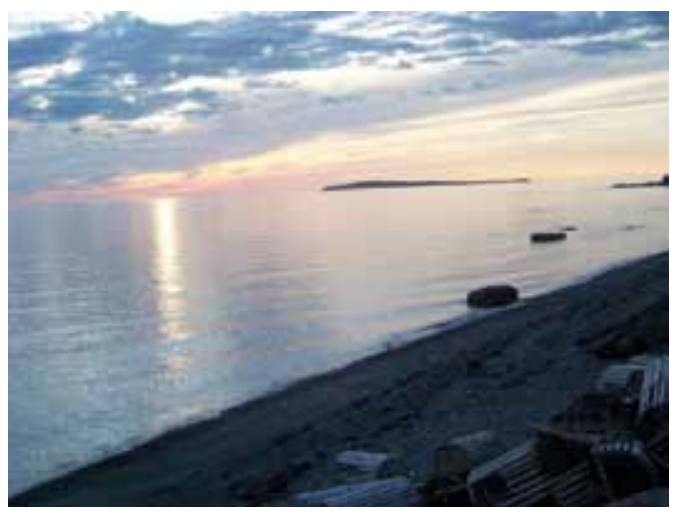

be likened to the tides. For sincere and open conversation involves constant give and take and a process of inevitable change, just as the tides ebb and flow and change what they touch in multifarious, often indiscernible ways. And, like the tidal wonder, the process of discovery for the teachers of this study held great beauty. Each teacher expressed a sense of discovery, moments in which they realized that they were undergoing change, moments of wonder or a sense of being involved in something not of natural but human beauty. There are, indeed, fewer things as beautiful as learning, and all of the teachers learned about themselves as teachers and about how in future they would apply what they had discovered in conversations in an online course to the challenges of teaching reading.

\section{New understandings gained regarding online teaching.}

Stepping back to consider insights gained while lacking the comfort and familiarity of a real classroom environment and experiencing instead an intangible world that initially seemed to merely mimic a real classroom environment took time, intentional planning, openness, and trial and error. While I discovered that many strategies for teaching online were similar to those used in face-to-face teaching, I also realized that many of these strategies could not be perfectly replicated in a virtual setting. It took time to become accustomed to hearing different voices, or tones, to understanding intentions, to interpreting meaning, to reading what teachers were attempting to relate in conversation. I realized (as mentioned earlier) that I needed to redefine myself in light of the change in landscape (Meloncon, 2007). Sorting out what I could continue to do, what I needed to make adjustments to, and what I needed to abandon, became part of the process of my transformation and integration into online instruction. Paying attention to what worked well was particularly helpful; picking up how teachers responded to my tone, choice of words, attempts to 
listen attentively, and activities for engagement in the course informed my instruction and moved me forward successfully.

Most importantly, through this study I learned that successful online teaching does not just happen. The process is complex and multifaceted, and must begin with the creation of a positive and safe learning space for open and sincere dialogue. As Lock (2006) points out, "[t]he creation of a safe and trusting space, the relevancy and currency of content in meeting the needs of the learners, the nature and richness of online discussions, and the nature of participation and interaction" (p. 674) are all factors that must be considered to ensure a successful online environment. Attention to each of these details enabled me to see the potential for learning in an online setting and to become comfortable in an environment that I initially felt uncomfortable in. Furthermore, I learned that engaging in such activities as discussion threads actually benefitted teachers in ways that I had not experienced in a face-to-face setting. By having time to participate thoughtfully and deliberately in written discussions, teachers had opportunity to discuss what mattered most to them. Finally, I learned that flexibility and negotiation are also an integral part of successful learning online. Respecting and assessing the needs of teachers, including the demands in their lives and competing priorities, goes a long way to earning their respect and creating a stress-free and predominantly joyful environment.

\section{Did teachers gain new insights about teaching reading through nego- tiation and attention to the environment created for their learning?}

In our online course teachers gained insights and deeper understanding about the reading process in numerous ways:

- revisiting their own assumptions about learning to read and teaching others to read

- deepening their understanding of how to create effective learning environments within their own contexts to promote reading

- increasing their knowledge in regard to comprehension, vocabulary, fluency, writing, and other components of language acquisition

- realizing more fully the complexity of both learning to read and teaching others to read

- resolving to consider what their future teaching might entail

- awakening to the fact that when they give expression to their insights, their new-found knowledge becomes relevant on a new level-they gain confidence to transform their practice and re-story how they live their daily lives in teaching 
While the focal point of this study was not to delve into what knowledge teachers gained about reading during our online course, the learning that did occur suggests that the proper environment was created. Attending to many factors is essential, including finding ways to allow all participants to speak, encouraging attentive listening (which inevitably leads to thoughtful response), ensuring security, and facilitating the course in a selfless way with the interests of participants at heart.

\section{Setting the conditions for learning by promoting sincere dialogue in an online setting?}

Rogers and Babinski (2002) emphasize that there is great potential for supporting teachers "through the creation of dialogic communities" (p. 41). In other words, conversation alone is not enough. Teachers benefit from having such conversations within a social context, especially an open and inviting context that encourages dialogue through mutual respect, concern for each other, and genuine listening. Throughout the course the experiences related by teachers in trying to teach reading were often difficult, and having opportunity to discuss the difficulty genuinely helped them move forward. In this respect it is critical that space and opportunity be provided for teachers to talk. By adhering to what took place during the course and recognizing the importance of dialogue, teachers would see the relevance of open conversation in their own contexts and lives. They would come to realize that on more than one level through dialogue they gain the support and confidence needed to progress in a profession that is often complex. They would also come to realize that through conversation and sharing stories, they gain voice and opportunity to revisit their beliefs, and to re-story their teaching lives. Beyond thinking about dialogue and sharing of stories to gain agency, the kinds of stories teachers share must include those that get at the heart of practice. This can be influenced by talking to other teachers who will push them to rethink, yet again, some of their assumptions about teaching.

Finally, there were times in some discussion threads when the teachers engaged in disagreements, the conversation pushing them to think harder about their teaching approaches and methodologies. Having open and honest dialogue concerning some of the contentious issues that we face gives teachers a valuable opportunity to test ideas and to debate what they believe. As Rogers and Babinski (2002) state, "Despite its potential for encouraging confirmation and the building of community, dialogue also offers the potential for debate and criticism" (p. 54). Tense moments inevitably occur, especially when devoted teachers discuss a topic they have strong opinions about or that is deeply relevant to their work or beliefs. However, through such conversations we come to see that gaining greater understanding 
and knowledge about teaching reading is not necessarily about agreeing with one another, and that by talking freely and openly we can discover new ways of looking at how and why we teach as we do. An example of this from a later thread in our study occurred when Holly and Millie discussed fluency in reading. Holly raised questions about the necessity of reading fluently in order to gain meaning from the text and was captivated by the notion that reading fluently may not be necessary for comprehension. In response to this, Lily shared an entirely different view. She explained how she found that when she could help a student become a faster, more fluent reader, the student's attitude became more positive and his or her comprehension level increased. Through this conversation we come to see that gaining greater understanding and knowledge about teaching reading is not necessarily about agreeing with one another, and that by talking freely and openly we can discover new ways of looking at how and why we teach as we do. In the case of this course, when the proper conditions were created for open and honest dialogue, disagreements usually led to respectful inquiry, because they were not tainted by competition, self-interest, or prejudice. During our course I continually witnessed teachers asking honest and sincere questions and seeking ways to encourage other members of the class.

The teachers in my first online course about teaching reading demonstrated that they had undergone a process of change. I have thought of this process as being like the endless process of the tides, at least in the way that the tidal ebb and flow can be said to bring about change for the better. That, after all, is what learning is all about.

\section{References}

Atkinson, R. (1995). The gift of narratives: Practi$\mathrm{cal}$ and spiritual applications of autobiography, life narratives, and personal mythmaking. Westport, CT: Bergin \& Garvey.

Barab, S., Kling, R., \& Gray, J. H. (Eds.). (2004). Designing for virtual communities in the service of learning. Cambridge, University Press.

Butler-Kisber, L. (2010). Qualitative inquiry: Thematic, narrative and arts-informed perspectives. London: Sage Publications Ltd.

Coleman, S. (2012). What are the benefits to teaching online? Retrieved from http:// www.worldwidelearn.com/educationarticles/benefits-of-teaching-online.htm

Conrad, D. (2005). Building and maintaining community in cohort-based online learning. Journal of Distance Education, 20(1), 1-21.

Duke, N.K., Purcell-Gates, V., Hall, L.A., \& Tower, C. (2006). Authentic literacy activities for developing comprehension and writing. The Reading Teacher, 60(4), 344-355.

Fiszer, E. (2004). How teachers learn best: An ongoing professional development model. Maryland: Scarecrow Education. 
Friesen, N., \& Anderson, T. (2004). Interaction for lifelong learning. British Journal of Educational Technology, 35(6), 679-688.

Graham, D. (2000). Weaving the voices: breaking the silence of isolation. (Unpublished master's thesis). St. Francis Xavier University, Antigonish, Nova Scotia.

Hargreaves, A. (2003). Teaching in the knowledge society: education in the age of insecurity. New York: Teachers College Press.

Hurt, J., \& Brush, T. (2009). Teacher participation in online communities: Why do teachers want to participate in self-generated online communities of K-12 teachers? Journal of Research on Technology in Education, 41(3), 279-303.

Lock, J. V. (2006). A new image: Online communities to facilitate teacher professional development. Journal of Technology and Teacher Education, 14(4), 663-678. Research Library.
Meloncon, L. (2007). Exploring electronic landscapes: Technological communication, online learning, and instructor preparedness. Technical Communication Quarterly, 16(1), 31-53.

Palloff, R. M., \& Pratt, K. (1999). Building learning communities in cyberspace. San Francisco: Jossey-Bass.

Roberts, T. S., \& Mclnnerney, J. M. (2007). Seven problems of online group learning (and their solutions). Educational Technology \& Society, 10(4), 257-268.

Rogers, D., \& Babinski, L. (2002). From isolation to conversation: Supporting new teachers' development. New York: State University of New York Press.

Tovani, C. (2000). I read it but don't get it: Comprehension strategies for adolescent readers. Portland, ME: Stenhouse.

Trathen, W., \& Moorman, G. (2001). Using e-mail to create pedagogical dialogue in teacher education. Reading Research and Instruction, 40(3), 203-224.

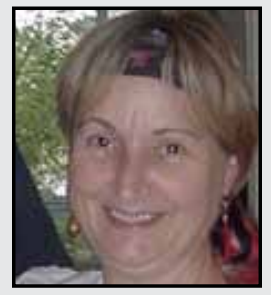

Deborah Graham is an Assistant Professor at St. Francis Xavier University in Antigonish, Nova Scotia, where she teaches courses in middle school pedagogy, assessment, and literacy at the B.Ed. level, and literacy and various other courses at the M.Ed. level. Prior to joining the Faculty of Education she was a public school teacher and regional administrator for many years. Her research interests include middle school pedagogy and teacher professional development, including the role of conversation in enhancing teacher professional knowledge. 